\title{
CÓNYUGES, FAMILIARES Y COMPAÑEROS: APROXIMACIÓN A LA TIPOLOGÍA DE LOS DEDICANTES EN LA EPIGRAFÍA GLADIATORIA ROMANA
}

\author{
Miguel Martínez Sánchez \\ Universidad de Murcia \\ miguel.martinez10@um.es \\ ORCID: 0000-0003-2180-9071
}

\section{SPOUSES, FAMILY MEMBERS AND PARTNERS: \\ APPROXIMATION TO THE TYPOLOGY OF DEDICANTS IN ROMAN GLADIATORY EPIGRAPHY}

\begin{abstract}
RESUMEN: Se plantea un estudio de todos los epígrafes funerarios conservados en las provincias occidentales en los cuales los dedicantes son gladiadores o sus personas más cercanas, como las parejas o compañeros y amigos. Se establece un análisis sobre la familia y los compañeros del ludus como principales participantes en el ritual funerario. A través de una recopilación epigráfica y de las fuentes latinas, se repasa la situación legal y socioeconómica de los gladiadores como factor influyente en este fenómeno. Finalmente, se incorporan una serie de mapas y tablas relacionadas con los datos técnicos y espaciales de todos aquellos epígrafes de este perfil.
\end{abstract}

PALABRAS CLAVE: Munus gladiatorium; epigrafía; coniunx; uxor; familia gladiatoria.
SUMMARY: We propose a study of every funerary epigraph in the occidental provinces in which the dedicants are gladiators or their closest people, such as partners or colleagues. It is also established an analysis of the importance of the family and the companions of the ludus as the main responsible for the duty towards the deceased ones. Through an epigraphic review of the Latin sources, we attempt to clarify the legal and socio-economic situation in which gladiators were located. Finally, a series of maps and tables are included, in relation to the technical and spatial data of all the archaeological pieces of this kind in order to improve our knowledge about the location and characteristics of these epigraphs.

KEYWORDS: Munus gladiatorium; epigraphy; coniunx; uxor; familia gladiatoria.

RECIBIDO: 23/01/2019. ACEPTADO: 25/03/2019 


\section{Universidad de Sevilla 50 - 2019}

FILOLOGÍA CLÁSICA

HISTORIA ANTIGUA

ARQUEOLOGÍA CLÁSICA

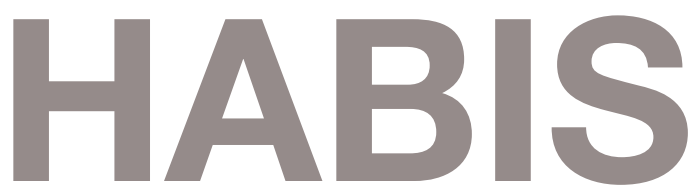




\section{HABIS}

50

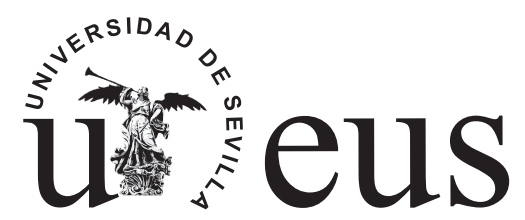

Editorial Universidad de Sevilla

SEVILLA 2019 
Reservados todos los derechos. Ni la totalidad ni parte de este libro pueden reproducirse o transmitirse por ningún procedimiento electrónico o mecánico, incluyendo fotocopia, grabación magnética o cualquier almacenamiento de información y sistema de recuperación, sin permiso escrito de la Editorial Universidad de Sevilla.

\section{DIRECTORES \\ Rocío Carande Herrero y Pilar Pavón Torrejón}

\section{CONSEJO DE REDACCIÓN}

Luis Ballesteros Pastor (Universidad de Sevilla, España), José Luis Escacena Carrasco (Universidad de Sevilla, España), José Beltrán Fortes (Universidad de Sevilla, España), Antonio Bravo García (Universidad Complutense, España), Antonio Caballos Rufino (Universidad de Sevilla, España), José María Candau Morón (Universidad de Sevilla, España), Francisca Chaves Tristán (Universidad de Sevilla, España), Juan Fernández Valverde (Universidad Pablo de Olavide, España), Enrique García Vargas (Universidad de Sevilla, España), Pilar León Alonso (Universidad de Sevilla, España), José María Maestre Maestre (Universidad de Cádiz, España), José Luis Moralejo Álvarez (Universidad de Alcalá, España), Salvador Ordóñez Agulla (Universidad de Sevilla, España), Antonio Ramírez de Verger (Universidad de Huelva, España), José Miguel Serrano Delgado (Universidad de Sevilla, España), José Solís de los Santos

(Universidad de Sevilla, España), Francisco Villar Liébana (Universidad de Salamanca, España)

\section{SECRETARIOS}

Francisco José García Fernández y José Miguel Jiménez Delgado

\section{CONSEJO ASESOR}

Rutger J. Allan (Universidad de Amsterdam, Holanda), Manuel Bendala Galán (Universidad Autónoma de Madrid, España), Alberto Bernabé Pajares (Universidad Complutense de Madrid, España), Genaro Chic García (Universidad de Sevilla, España), José Antonio Correa Rodríguez (Universidad de Sevilla, España), Francisco Javier Fernández Nieto (Universidad de Valencia, España), Manuel García Teijeiro (Universidad de Valladolid, España), Juan Gil Fernández (Universidad de Sevilla, España), Luis Gil Fernández (Universidad Complutense, España), Cristóbal González Román (Universidad de Granada, España), Javier de Hoz Bravo (†) (Universidad Complutense, España), Simon J. Keay (Universidad de Southampton, Reino Unido), Peter Kruschwitz (Universidad de Viena, Austria), Francisco J. Lomas Salmonte (Universidad de Cádiz, España), Jesús Luque Moreno (Universidad de Granada, España), José María Luzón Nogué (Universidad Complutense, España), M. ${ }^{a}$ Cruz Marín Ceballos (Universidad de Sevilla, España), Patrizio Pensabene (Universidad de Roma "La Sapienza”, Italia), Miguel Rodríguez-Pantoja Márquez (Universidad de Córdoba, España), Diego Ruiz Mata (Universidad de Cádiz, España), Eustaquio Sánchez Salor (Universidad de Extremadura, España), Bartolomé Segura Ramos (Universidad de Sevilla, España), Emilio Suárez de la Torre (Universidad Pompeu Fabra, España), Nicolas Tran (Universidad de Poitiers, Francia)

Este volumen ha sido parcialmente financiado por las Facultades de Filología y Geografía e Historia de la Universidad de Sevilla.

(C) Editorial Universidad de Sevilla 2019

c/ Porvenir, 27. 41013 Sevilla

Teléfonos: 954487446 - 74 51. Fax: 954487443

Correo electrónico: eus4@us.es

http://www.editorial.us.es

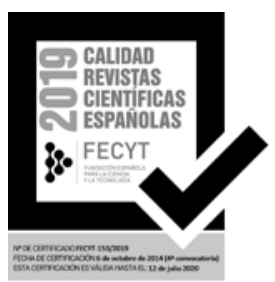

Impreso en España-Printed in Spain

ISSN 0210-7694

DOI: http://dx.doi.org/10.12795/Habis

Depósito Legal: SE-669-1994

Maquetación: Referencias Cruzadas - referencias.maquetacion@gmail.com

Impresión: Pinelo Talleres Gráficos, s.1.-Salteras. Sevilla 


\section{ÍNDICE}

JUAN GIL. Los primeros años de Habis ……................................................. 7

JOSÉ MARÍA LUZÓN NOGUÉ. Así nació la revista Habis............................. 11

DIEGO RUIZ MATA. Años recordados por la revista Habis.............................. 15

JOSÉ ANTONIO CORREA RODRÍGUEZ. Javier de Hoz Bravo, helenista y paleohispanista

RAÚL SÁNCHEZ CASADO. El servidor del $k a$ y la pureza ritual: algunas notas sobre la escena de circuncisión en la tumba de Ankhmahor

ANTONIO MANUEL SÁEZ ROMERO / MARÍA LUISA LAVADO

FLORIDO. Cremaciones fenicias y un nuevo saladero de pescado púnico de Gadir. Avance de los hallazgos registrados en el área de Los Chinchorros (Calle San Bartolomé, Cádiz)

ALEJANDRO ABRITTA. Una nueva perspectiva sobre el problema de la performance de los mimiambos de Herodas

ANTONIO RUIZ CASTELLANOS. Hasta Regia y la cultura religiosa fenicia

AGUSTÍN MORENO. Motivos griegos en el episodio de Tito Livio del ataque de Porsena a Roma

GORETTI OYA GARCÍA. Genetrix Orbis. Madre de la dinastía JulioClaudia, madre del Imperio, madre del orbe. La imagen de Livia Drusila en el territorio de la Bética

FRANCISCO CIDONCHA REDONDO. Mujeres infames en la sociedad romana del Alto Imperio

MIGUEL MARTÍNEZ SÁNCHEZ. Cónyuges, familiares y compañeros: aproximación a la tipología de los dedicantes en la epigrafía gladiatoria romana

JOSÉ M. CANDAU MORÓN / FÁTIMA AGUAYO HIDALGO. Sangre judía en odres griegos. Flavio Josefo y la historiografía griega

ALBERTO ROMERO CRIADO. Análisis semántico de los lexemas vṽv y voví en el Nuevo Testamento

ANA C. VICENTE SÁNCHEZ. Intercambios epistolares entre Darío y Alejandro. Perspectiva intertextual desde la plutarquea Vida de Alejandro ..

JOSÉ D’ENCARNAÇÃO. ¿Uma inscrição romana em S. Martinho do Porto?. 
SALVADOR ORDÓÑEZ AGULLA / SERGIO GARCÍA-DILS DE

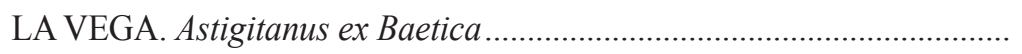

JOSÉ ANTONIO CORREA RODRÍGUEZ. El hidrónimo Tader (Río Segura).

ELEONORA GIUNCHI. Amor abrasador: carbones y brasas en los epigramas eróticos de la Antología Palatina

MATTIA C. CHIRIATTI. Il De oratione dominica. Nisseno ed i commenti esegetici anteriori: uno studio comparativo

PETER KRUSCHWITZ. How the Romans Read Funerary Inscriptions:

Neglected Evidence from the Querolus

STÉPHANIE GUÉDON. El cristianismo en el extremo Occidente africano en la Antigüedad tardía: una presencia religiosa sometida a discusión ......

PEDRO CASTILLO MALDONADO. La Epistola ad Vincentium de Liciniano de Cartagena y la tradición de la Epistola de die Sancto Dominico en la Spania bizantina

FRANCISCO SALVADOR VENTURA. La Historia Wambae de Julián de Toledo y sus caracteres de historiografía clásica

A. Álvarez-Ossorio Rivas, E. Ferrer Albelda y Á. Delgado Pereira (coords.), Guerra y Paz. Las religiones ante los conflictos bélicos en la Antigüedad, Spal Monografías no XXIII (Judit Mata Soler) 409 • A. F. Caballos Rufino, Hispalis, de César a Augusto. La Colonia Romula y los orígenes institucionales de la Sevilla romana entre la República y el Imperio (Víctor A. Torres González) 411 • J. Gil, Chronica Hispana saeculi VIII et IX, Corpus Christianorum Continuatio Mediaeualis LXV (Juan Martos) 414 • H. Jiménez Vialás, Carteia y Traducta. Ciudades y territorio en la orilla norte del Estrecho de Gibraltar (siglos VII a. C.-III d. C.), Col-lecció Instrumenta 57 (Sergio España-Chamorro) 416 • J. J. Justel, A. García-Ventura (eds.), Las mujeres en el Oriente cuneiforme (Daniel León Ardoy) 420 • C. Martínez López y P. Ubric Rabaneda (eds.), Cartografías de género en las ciudades antiguas (Colección Feminae) (Julia Guantes García) 424 • Á. Narro, Platón. El Banquete, Colección Rhemata Textos Griegos, volumen 1 (Carmen Sánchez-Mañas) $426 \bullet \mathrm{M}$. Navarro Caballero, Perfectissima femina. Femmes de l'élite dans l'Hispanie romaine. 2 vols (Francisco Cidoncha Redondo) $429 \bullet$ G. Ottone - A. L. Chávez Reino, Teopompo di Chio. Filippiche (Fozio, Biblioteca, cod. 176), (Álvaro Ibáñez Chacón) 431 - S. Panzram y L. Callegarin (eds.), Entre civitas y madina. El mundo de las ciudades en la Península Ibérica y en el Norte de Árica (siglos $I V-I X)$. (Jerónimo Sánchez Velasco ) 434 • P. Pavón (ed.), Marginación y mujer en el Imperio romano, (Salvador Ordóñez Agulla) $436 \bullet$ F. Prados Martínez, H. Jiménez Vialás y J. J. Martínez García (Coords.), Menorca entre fenicis i púnics. Menorca entre fenicios y púnicos, (Francisco José García Fernández) 441 • D. Quint, Virgil's Double Cross. Design and Meaning in the Aeneid (María Emilia Cairo) 446 - J. Rodríguez Mellado, P. Garrido González y J. Vázquez Paz (eds.), La necrópolis tardoantigua de la Plaza del Humilladero de Ntra. Sra. de Regla (Chipiona, Cádiz): primera 
campaña de excavaciones arqueológicas (2015) (Luis Gethsemaní Pérez Aguilar) 449 • M. Sánchez Romero, R. M ${ }^{\mathrm{a}}$ Cid López, Motherhood and Infancies in the Mediterranean in Antiquity (Marta Álvaro Bernal) 453 • C. Sierra Martín, Tucídides Archaiologikós. Grecia antes de la Guerra del Peloponeso, (Marc Mendoza Sanahuja) 456 - N. A. Vitiglio, Il lessico miceneo riferiti ai cereali (José Miguel Jiménez Delgado) 457 • J. Untermann, Monumenta Linguarum Hispanicarum. Band VI. Die vorrömische einheimische Toponymie des antiken Hispanien, (José Antonio Correa Rodríguez) 461 • VVAA. Costruzione e decostruzione della cartografia tolemaica. Número monográfico de Geographia Antiqua 26 (Gonzalo Cruz Andreotti) 466 


\section{INTRODUCCIÓN}

La gladiatura o munus gladiatorium ha sido un tema de estudio muy relevante en la última década para la producción académica en castellano․ Desde la segunda mitad del siglo XX y con el comienzo del nuevo milenio, hemos pasado de contar con apenas algunos trabajos elementales en todo el mundo ${ }^{2}$ a llegar a un punto de conocimiento que nos ha permitido redescubrir los munera como deporte $^{3}$, negocio y espectáculo de masas en la Antigüedad ${ }^{4}$. Actualmente, el munus o los munera gladiatoria, término generalmente aceptado ${ }^{5}$, sigue siendo una de las actividades más interesantes para conocer la cultura clásica, la organización económica de los espectáculos, la jerarquización social de quienes lo componían, las raíces culturales de los $l u d i$, su utilización en la política como herramienta propagandística ${ }^{6}$, así como todo el sistema sociopolítico del Imperio Romano y su capacidad para replicarse en el espacio del Mediterráneo ${ }^{7}$. Munera gladiatoria, ludi circenses y uenationes fueron, en suma, los espectáculos más demandados por la población romana, de ahí que sigan siendo de los más conocidos entre el público general ${ }^{8}$, aunque todavía perviva en el imaginario colectivo el relato transmitido por los apologetas cristianos ${ }^{9}$, quienes vieron la gladiatura como un reflejo de una sociedad romana adicta a la violencia y el derroche ${ }^{10}$.

La perspectiva académica actual ha podido desvelar cómo los munera también fueron considerados una forma más de vida, organizada como un negocio y diferenciada de las condenas a muerte (noxii), las cuales también se celebraban en el anfiteatro. A pesar de que la gladiatura estaba diseñada como un espectáculo de masas con ciertos toques teatralizados, la muerte fue un elemento clave para entenderla, si bien sabemos que el fallecimiento de un gladiador era muy caro para el lanista, de ahí que se optase por desarrollar combates reglados que evitasen muertes innecesarias. El público esperaba de los gladiadores una actitud de valentía frente a la muerte, de superación de la misma, más que su propia muerte

${ }^{1}$ Cf. Pastor 2018; Mendoza 2018; AA.VV. 2017; Cidoncha 2017; López y Pérez 2017; Pastor 2017; Muñoz 2017a; Muñoz 2017b; Muñoz 2016a; Muñoz 2016b; Egea y Arias 2015; Erme 2014; Pastor y Pastor 2013a; Pastor y Pastor 2013b; Pastor y Pastor 2013c; Mañas 2013; Muñoz 2012; Pastor y Mañas 2012; Eguiarte 2012; Perea; 2012; Del Pino 2011; Jiménez 2011; Vaquerizo 2011; Giménez 2010; Pastor y Mañas 2010; Pastor y Pastor 2009; Jiménez 2009.

${ }^{2}$ Robert 1940; Guttmann 1978; Ville 1981.

${ }^{3}$ Dunkle 2013; Crowther 2007; Futrell 2006; Mahoney 2001.

${ }^{4}$ Köhne y Weigleben 2000.

${ }^{5}$ Ceballos y Ceballos 2011: 107.

${ }^{6}$ Knapp 2011; Enenkel 2005.

${ }^{7}$ Plass 1995: 65.

${ }^{8}$ Pastor 2016: 142.

${ }^{9}$ González 2013: 355-370.

${ }^{10}$ Wiedermann 1992: 128. 
física $^{11}$, hecho que tiene más relación con las virtudes marciales inculcadas generación tras generación ${ }^{12}$ que con la realidad histórica del deporte.

De acuerdo a la información del cementerio de Éfeso, la edad media de fallecimiento de los gladiadores estuvo entre los 20 y 30 años $^{13}$, similar a los 27 años de media que aparecen en los epígrafes de las provincias imperiales ${ }^{14}$, con una media de 3 torneos por año ejercido ${ }^{15}$. Aunque esta edad de fallecimiento es menor que la de los aurigas o actores, resulta lógico pensar que los gladiadores pudiesen fallecer, bien por infecciones posteriores, heridas mortales o por ejecución en la arena (iugulum).

\section{LA EPIGRAFÍA FUNERARIA COMO FUENTE DE CONOCIMIENTO DE LA VIDA PRIVADA GLADIATORIA}

La epigrafía nos ofrece una ventana hacia la concepción de la muerte en el mundo gladiatorio romano. Sabemos, por la forma en la que se van repitiendo las inscripciones en todo el territorio mediterráneo occidental, que se estableció en las tumbas un esquema fijo que aparece, con leves variaciones, en prácticamente todos los $\operatorname{casos}^{16}$ : armatura, nombre, ludus, pugnae/uictoria, status, origo, edad, dedicante y fórmula funeraria. Dadas las circunstancias sociales de los gladiadores y la visión subjetiva de los autores clásicos, resulta interesante acercarse a la figura de los dedicantes en la epigrafía funeraria. Estas personas sin duda formaron parte del día a día de los gladiadores, componiendo sus familias en lo sentimental y biológico, pero también a nivel de hermandad como el caso de la familia gladiatoria.

Dentro de las fuentes clásicas que hacen mención al munus gladiatorium, encontramos todo un elenco de autores que tratan el tema desde diferentes puntos de vista. Tomando como referencia la tesis de Alfonso Mañas, de los 104 autores clásicos que menciona, al menos 77 hablan directa o indirectamente de combates rituales o competitivos, bien predecesores o como gladiatura romana ${ }^{17}$.

A día de hoy, las mejores obras para el estudio de los epígrafes latinos son Epigrafia anfiteatrale dell'Occidente romano, cuyos nueve volúmenes (desde 1988 hasta 2017), han actualizado toda la información descubierta hasta la fecha en las provincias occidentales. Por otro lado, el mejor motor de búsqueda digital es la Epigraphische Datenbank Clauss-Slaby, repositorio constantemente

\footnotetext{
${ }^{11}$ Carter 2007: 101; Edwards 2007: 23.

${ }^{12}$ Muñoz 2013: 57; Naselli 2010.

${ }^{13}$ Kanz y Grosschmidt 2006: 210; Grosschmidt y Kanz 2002.

${ }^{14}$ Pastor 2016: 175.

${ }^{15}$ Junkelmann 2000: 47.

${ }^{16}$ Ceballos 2003: 315.

${ }^{17}$ Mañas 2013: 449-453.
} 
actualizado en materia de información epigráfica. Tras una búsqueda en dicha base de datos de diferentes términos y su correlación con volúmenes publicados de Epigrafia anfiteatrale dell'Occidente romano, se han encontrado un total de 86 inscripciones donde se encuentran referencias relativas a los encargados de la obra funeraria del gladiador.

\section{LAS MUJERES COMO DEDICANTES}

De los 86 resultados obtenidos en la búsqueda epigráfica, contamos con 50 piezas donde se cita a una mujer relacionada con gladiador de manera explícita (esposa, hija o madre), conformando el $58 \%$ de todos los resultados. Solo existe un caso documentado en el que la dedicante sea la madre, una inscripción del siglo II d. C. encontrada en Roma, donde tanto el fallecido como la madre portan dua nomina (CIL VI, 10179). En general las dedicantes son las parejas sentimentales. La denominación más utilizada es coniunx (26 casos), seguida de uxor (10 casos), la mención única del nombre de ella (10 casos), contubernalis (3 casos) y la alusión a maritus ( 2 casos, uno donde indica su cognomen y otro donde indica que es uxor). Además, hay dos inscripciones donde la mujer se autodenomina 'hija' o filia (3 casos, uno en el que la hija es la enterrada).

Un aspecto que llama la atención es la nomenclatura con la que se denominan a sí mismas las esposas (uxor y coniunx), términos que no parecen coincidir con el sustantivo contubernalis, más acorde a la situación legal de los gladiadores. De acuerdo a la legislación romana, los gladiadores tenían infamia, situación legal derivada de la realización de actividades en las cuales exponían sus cuerpos, una categoría que compartían con los actores, bailarines, proxenetas, prostitutas y participantes activos en los ludi (Coll. 4.3.2; Dig. 3.1.1.6, Vlp. dig. 3.2.1) ${ }^{18}$. $\mathrm{Al}$ adquirir la condición de infamis, los gladiadores estaban en una situación jurídica que les impedía hacer testamento o tener ius conubii ${ }^{19}$, por lo que el término correcto debería ser contubernalis.

Por otro lado, sabemos por las fuentes clásicas que los gladiadores tenían gran fama en el público. De hecho, nos aparecen en multitud de soportes como mosaicos, pinturas murales y objetos materiales, principalmente lucernas, e incluso figuras de terracota, de gran popularidad en Hispania $^{20}$ y posiblemente usadas como una especie de juguetes infantiles ${ }^{21}$. Epicteto llega incluso a narrar una escena de niños jugando a ser gladiadores (Disc. 29.4). De manera paralela, los múltiples graffiti expresan ese 'producto casual e instintivo de las emociones de

\footnotetext{
${ }^{18}$ Pastor y Pastor 2009: 180; Edwards 1997: 67.

${ }^{19}$ Mañas 2013: 242.

${ }^{20}$ Blázquez 1958: 80-94.

${ }^{21}$ Potter 2006: 403.
} 
CÓNYUGES, FAMILIARES Y COMPAÑEROS: APROXIMACIÓN A LA TIPOLOGÍA...

\begin{tabular}{|c|c|}
\hline \multicolumn{2}{|r|}{ EPÍGRAFES GLADIATORIOS CON DEDICANTES MUJERES } \\
\hline \multicolumn{2}{|r|}{ CONIVNX } \\
\hline \multicolumn{2}{|r|}{ ITALIA } \\
\hline Roma & $\begin{array}{l}\text { CIL VI, 10167; EAOR I, } 66 \\
C I L \text { VI, 10178; EAOR I, } 69 \\
C I L \text { VI, 10177; CIL VI, } 33977 ; \text { CIL XIV, 293, 2; EAOR I, } 73 \\
\text { CIL VI, 10176; EAOR I, } 74 \\
\text { AE 1989, 74; EAOR I, } 76 \\
\text { CIL VI, 10193; EAOR I, } 91 \\
\text { CIL VI, 10195; EAOR I, } 93\end{array}$ \\
\hline Beneuentum & $A E$ 1960, 139; AE 1960, 140; EAOR III, 69 \\
\hline Aquileia & CIL V, 1037; EAOR II, 48 \\
\hline Patauium & CIL V, 2884; EAOR II, 43 \\
\hline Verona & CIL V, 3468; EAOR II, 52 \\
\hline Brescia & $\begin{array}{l}\text { AE 1908, 222; EAOR II, } 41 \\
C I L \mathrm{~V}, 4506 ; E A O R \text { II, } 45\end{array}$ \\
\hline Puteoli & $\begin{array}{l}\text { CIL X, 1927; EAOR VIII, } 28 \\
\text { CIL X, 1926; EAOR VIII, } 29 \\
\text { CIL X, 1734; EAOR VIII, } 30\end{array}$ \\
\hline \multicolumn{2}{|r|}{ DALMATIA } \\
\hline Salona & $A E$ 2001, 1622; $A E$ 2011, 928; CIL III, 8830 \\
\hline \multicolumn{2}{|r|}{ GALLIA NARBONENSIS } \\
\hline Nemausus & $\begin{array}{l}\text { CIL XII, 3323; EAOR V, } 15 \\
\text { CIL XII, 3325; EAOR V, } 20 \\
\text { AE 2005, 970; CIL XII, 3327; EAOR V, } 21 \\
\text { CIL XII, 3329; EAOR V, } 24\end{array}$ \\
\hline Arausio & $\begin{array}{l}C I L \text { XII, } 5836 \\
C I L \text { XII, } 5837\end{array}$ \\
\hline \multicolumn{2}{|r|}{ LVGDVNENSIS } \\
\hline Lugdunum & CIL XIII, 1997; EAOR V, 62 \\
\hline \multicolumn{2}{|l|}{ BAETICA } \\
\hline Corduba & $\begin{array}{l}A E \text { 1962, 46; CIL II }{ }^{7}, 359 ; E A O R \text { VII, } 23 \\
A E \text { 1971, 179; CIL II } 7 \text {, 363; EAOR VII, } 25\end{array}$ \\
\hline
\end{tabular}


MIGUEL MARTÍNEZ SÁNCHEZ

\begin{tabular}{|c|c|}
\hline \multicolumn{2}{|r|}{ EPÍGRAFES GLADIATORIOS CON DEDICANTES MUJERES } \\
\hline \multicolumn{2}{|r|}{$V X O R$} \\
\hline \multicolumn{2}{|r|}{ ITALIA } \\
\hline Roma & $\begin{array}{l}A E \text { 2010, 225; CIL VI, 10170; EAOR I, } 51 \\
C I L \text { VI, 10202; EAOR I, } 52\end{array}$ \\
\hline Brixia & $A E$ 1991, 851 \\
\hline Tergeste & CIL V, 563; EAOR II, 19 \\
\hline Mediolanum & $A E$ 2003, 12; AE 2004, 627; AE 2006, 137; CIL V, 5933; EAOR II, 50 \\
\hline \multicolumn{2}{|r|}{ GALLIA NARBONENSIS } \\
\hline Nemausus & CIL XII, 3328; EAOR V, 22 \\
\hline \multicolumn{2}{|r|}{ BAETICA } \\
\hline Gades & $A E$ 1962, 57; CIL II, 1739; EAOR VII, 27; HEp 2009, 95 \\
\hline Corduba & $\begin{array}{l}\text { AE 1962, 52; CIL II }{ }^{7}, 53 ; \text { EAOR VII, } 20 \\
\text { AE 1962, 45; CIL II } 7 \text {, 365; EAOR VII, } 21 \\
\text { AE 1962, 48; CIL II }{ }^{7}, 361 ; \text { EAOR VII, } 24\end{array}$ \\
\hline \multicolumn{2}{|r|}{ NOMINA MVLIERVM } \\
\hline \multicolumn{2}{|r|}{ ITALIA } \\
\hline Roma & $\begin{array}{l}\text { EAOR I, } 54 \\
\text { EAOR I, } 82 \\
\text { CIL VI, } 10179\end{array}$ \\
\hline Aquileia & $A E 2003,680$ \\
\hline $\begin{array}{l}\text { Concordia } \\
\text { Sagittaria }\end{array}$ & CIL V, 1907; EAOR II, 37 \\
\hline Brixia & $A E$ 1991, 00825; EAOR II, 45a \\
\hline \multicolumn{2}{|r|}{ DALMATIA } \\
\hline Salona & $\begin{array}{l}A E \text { 2001, 1622; } A E \text { 2011, 928; CIL III, } 8825 \\
A E \text { 2011, 928; CIL III, 9413; CIL III, } 12851\end{array}$ \\
\hline \multicolumn{2}{|r|}{ LVSITANIA } \\
\hline Emerita Augusta & $\begin{array}{l}\text { AE 1962, 59; CIL II, 499; EAOR VII, } 28 \\
A E \text { 1989, 395; EAOR VII, 30; HEp 1990, } 39\end{array}$ \\
\hline \multicolumn{2}{|r|}{ CONTVBERNALIS } \\
\hline \multicolumn{2}{|r|}{ GALLIA NARBONENSIS } \\
\hline Nemausus & $\begin{array}{l}\text { CIL XII, 3324; EAOR V, } 9 \\
\text { EAOR V, } 27\end{array}$ \\
\hline
\end{tabular}


CÓNYUGES, FAMILIARES Y COMPAÑEROS: APROXIMACIÓN A LA TIPOLOGÍA...

\begin{tabular}{|c|c|}
\hline \multicolumn{2}{|r|}{ EPÍGRAFES GLADIATORIOS CON DEDICANTES MUJERES } \\
\hline \multicolumn{2}{|r|}{ MARITVS } \\
\hline \multicolumn{2}{|r|}{ ITALIA } \\
\hline Verona & $C I L \mathrm{~V}, 3466 ; C I L \mathrm{XI}, 129 \mathrm{~b} ; E A O R$ II, 47 \\
\hline Mediolanum & $A E$ 2003, 12; $A E$ 2004, 627; AE 2006, 137; CIL V, 5933; EAOR II, 50 \\
\hline \multicolumn{2}{|r|}{ FILIA } \\
\hline \multicolumn{2}{|r|}{ ITALIA } \\
\hline Roma & $\begin{array}{l}\text { AE 2012, 181; CIL VI, 4335; EAOR I, } 67 \\
\text { EAOR I, } 82\end{array}$ \\
\hline Mediolanum & $A E 2003,12 ; A E$ 2004, 627; $A E$ 2006, 137; CIL V, 5933; EAOR II, 50 \\
\hline
\end{tabular}

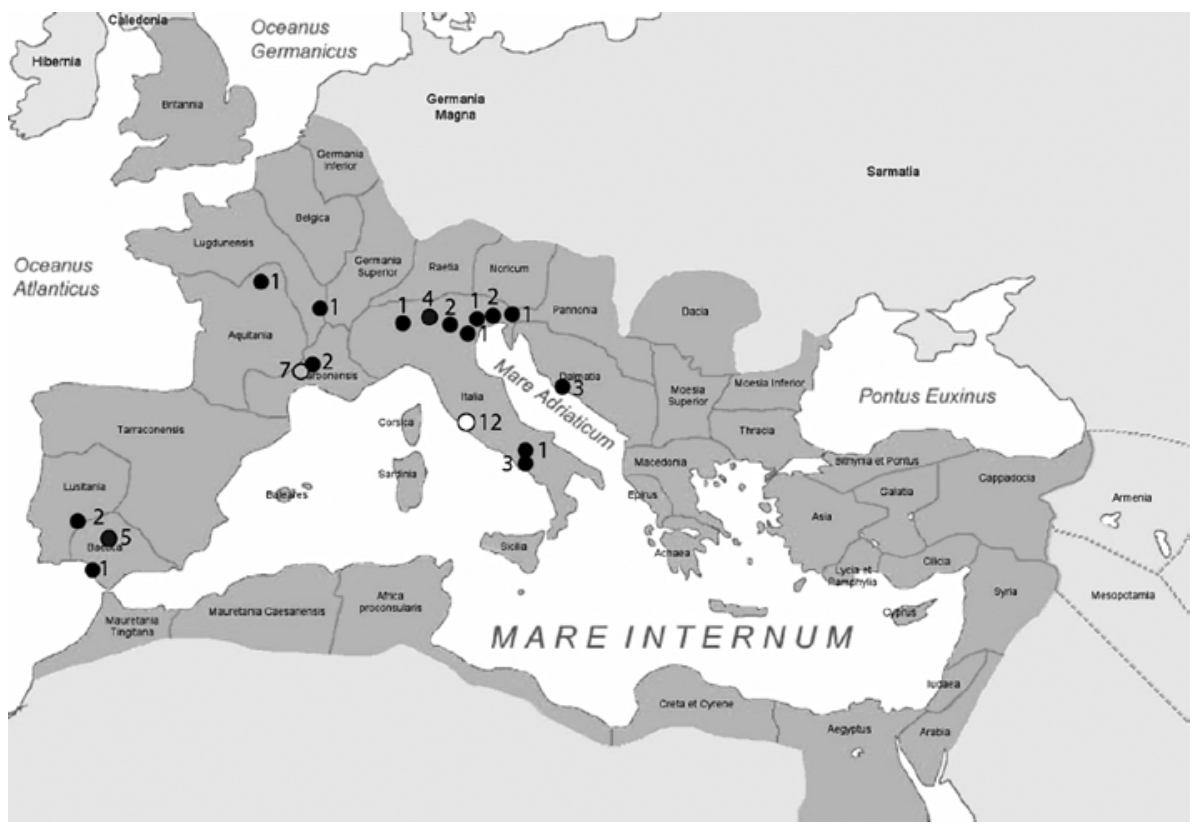

Figura 1. Mapa con los dedicantes femeninos en las provincias occidentales.

los contemporáneos que presenciaron el espectáculo gladiatorio ${ }^{22}$, reforzando la idea de que fue una actividad lúdica muy popular ${ }^{23}$.

Algunas fuentes clásicas utilizan esta fama de los gladiadores como excusa para la crítica al pueblo llano y a la aristocracia, con especial fijación en las

\footnotetext{
${ }^{22}$ Sabbatini 1988: 91.

${ }^{23}$ Wiedermann 1992: 24.
} 
mujeres. Petronio relata una conversación donde se cita la atracción sexual hacia los gladiadores (Petr. Sat. 126.7). Cipriano describe a los gladiadores como 'hombres apuestos' (honesta satis forma, ad Don. 7), fruto de las horas de entrenamiento y dedicación a la lucha. Tácito afirmaba al respecto: 'me da la impresión de que se contraen casi en el vientre de la madre los vicios exclusivos y peculiares de esta ciudad: me refiero a la afición por el teatro y el entusiasmo por los espectáculos de gladiadores y de caballos' (Tac. dial. 29) ${ }^{24}$. Ovidio afirmaba que las mujeres aprovechaban estos actos como forma de relacionarse socialmente y 'ser vistas' ("Spectantum ueniunt, ueniunt spectentur ut ipsae" Ov. ars 1.99). Juvenal cita, en tono de burla, el caso de Eppia, mujer aristocrática que abandonó a su familia para seguir a un gladiador (Iuv. 6.110-113). A finales del siglo II d. C., Tertuliano se burlaba del público, escribiendo que los hombres entregaban 'sus almas' y las mujeres 'sus cuerpos' (Tert. spect. 22). Tal era la pasión y el sentimiento que despertaban que, en ocasiones, los combates llegaban a estimular los ánimos del público hasta el punto de que los apologetas cristianos critican la proliferación de relaciones amorosas en las gradas (Tert. spect. 25.2; Clem. Al. Paed. 3.11.77. Incluso conservamos algunos graffiti pompeyanos en los cuales los gladiadores hacen gala de su fama entre las mujeres (CIL IV, 4342 'Celado Octaviano, tracio, tres victorias, tres coronas: suspiro de todas las chicas'; CIL IV, 4345 'Celado, tracio, placer de las mujeres'; $C I L$ V, 4356 'Crescente, reciario, amo y señor de todas las muñequitas'). Todas estas menciones no hacen sino confirmar el hecho de que los gladiadores pudiesen formar parejas y estableciesen sus familias en el $l u d u s^{25}$.

Dentro del registro epigráfico, los adjetivos con los que los gladiadores se refieren a sí mismos o sus allegados los denominan nos hace llegar una visión más positiva y familiar de sus vidas privadas. Encontramos fórmulas estereotipadas de cariño hacia el difunto, términos como dulcissimus, karissimus, desiderantisimus o pius ${ }^{26}$, entre otros. Esta manera de referirse al fallecido contrasta con la visión peyorativa que reflejan los autores clásicos, de extracto social mucho más alto en la época, quienes consideraban a los gladiadores infames y lo más bajo de la sociedad (Calp. decl. 52; Tac. ann. 1.76.3; Sen. benef. 6.12.2; Mart. 11.66; Cic. Tusc. 2.41; Plin. nat. 33.1; Quint. decl. 9.21), si bien otros defienden que los gladiadores eran mejor considerados en las regiones grecoparlantes (Nep. Epam. 2: "atque haec ad nostram consuetudinem sunt leuia et potius contemnenda; at in Graecia utique olim magnae laudi erant"). Esta situación social tan peculiar hacía que los gladiadores fuesen amados y odiados a la vez por su público, contradicción a la que hace alusión el apologeta Tertuliano (spect. 22) ${ }^{27}$.

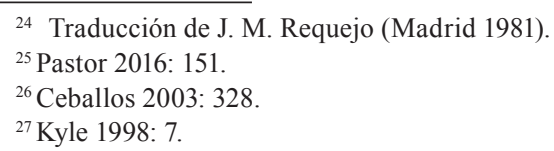




\section{COMPAÑEROS EN VIDA Y COMPAÑEROS EN MUERTE, LOS DEDICANTES VARONES}

Siguiendo con el desglose del registro epigráfico en latín, encontramos 36 casos en los cuales la obra funeraria fue dedicada por los compañeros en el combate. En la mayoría de los casos, aquellos se refieren a sí mismos con su armatura (11 casos), aunque también aparece una variedad de sinónimos como coarmio, conuictor, compatriota, conseruus, colliberato, contubernalis, tiro o su cognomen (13 casos), aunque también aparecen doctores (4 casos), los maestros especialistas en la lucha gladiatoria, o dueños de la tropa ( 2 casos). En otras inscripciones, el dedicante se refiere a sí mismo como sodalis (5 casos), amicus (4 casos) o frater (3 casos), si bien no podemos confirmar que se trate de un hermano biológico o una fórmula de amistad. En otros ejemplos, son los compañeros en conjunto los que hacen la obra funeraria, bien como familia uniuersa o gladiatoria ( 2 casos) o, en un caso dudoso, actuando como collegium (1 caso), posiblemente organizado para ayudarse mutuamente en caso de fallecimiento ${ }^{28}$. Además de las mujeres y compañeros, conservamos un epígrafe de un liberto dedicado a su patrono (CIL VI, 3393), así como una inscripción mandada realizar por el murmillo veterano Gaesus, en honor a su hijo Alcibiades (CIL VI, 10176).

Los resultados nos hacen ver que los compañeros del ludus participaron de manera activa en los rituales funerarios, sacrificando también el nombre real en virtud del cognomen artístico, tomado no como una vergüenza social sino un orgullo. Sabemos que el ludus hizo las veces de academia y de hogar de los gladiadores, sus parejas, en ocasiones llamadas ludiae y sus hijos. También conservamos alusiones al cuidado de los gladiadores de las esposas de compañeros fallecidos (Plu. Mor. 1099B) y pruebas arqueológicas de que mujeres y niños habitaban estos lugares. La vida en el ludus les permitía disfrutar de una serie de coberturas en materia de ejercicio físico y comida, enfocadas en que mejorasen su forma y adquiriesen un aspecto de gran tamaño y fortaleza, así como cierto tiempo libre fuera del mismo. Al tiempo, el entrenamiento tenía que ser rentable para los lanistae que llevaban el negocio, así como los editores, responsables en último término de que se cobrasen las cantidades de dinero pactadas.

El desarrollo del entrenamiento del gladiador en el ludus consistía no solo en un proceso de incorporación de un novato o tiro al servicio de un doctor, sino también en la entrada en la familia gladiatoria. Aquellos aspirantes que no pasaban este primer filtro iban a parar al grupo de los gregarii, mientras que los que demostraban tener las cualidades necesarias comenzaban su andadura bajo la dirección de los doctores y magistri especializados en cada armamento. El tiro iba rotando por cada estilo hasta encontrar aquella armatura que se ajustase mejor a su forma de pelear. Este sistema de aprendizaje nos recuerda al mundo militar, ya que seguía una jerarquía en la cual, en palabras de Pastor y Pastor "el estrato más

\footnotetext{
${ }^{28}$ Vaquerizo 2011: 96.
} 
MIGUEL MARTÍNEZ SÁNCHEZ

\begin{tabular}{|c|c|}
\hline \multicolumn{2}{|r|}{ EPÍGRAFES GLADIATORIOS CON DEDICANTES VARONES } \\
\hline \multicolumn{2}{|r|}{ ARMATVRA } \\
\hline \multicolumn{2}{|r|}{ ITALIA } \\
\hline Roma & $\begin{array}{l}C I L \text { VI, 10180; EAOR I, } 71 \\
C I L \text { VI, 7659; EAOR I, } 83 \\
C I L \text { VI, 10169; EAOR I, } 86\end{array}$ \\
\hline Rauenna & $A E$ 1990, 355; EAOR II, 42 \\
\hline $\begin{array}{l}\text { Thermae } \\
\text { Himeraeae }\end{array}$ & CIL X, 7364; EAOR III, 71 \\
\hline \multicolumn{2}{|r|}{ DALMATIA } \\
\hline Salona & $A E$ 2011, 928; CIL III, 2127; CIL III, 8595 \\
\hline \multicolumn{2}{|r|}{ GALLIA NARBONENSIS } \\
\hline Nemausus & CIL XII, 3330; EAOR V, 25 \\
\hline \multicolumn{2}{|r|}{ GERMANIA INFERIOR } \\
\hline $\begin{array}{l}\text { Colonia Clau- } \\
\text { dia Ara }\end{array}$ & $A E$ 1929, 110; EAOR V, 63 \\
\hline \multicolumn{2}{|r|}{ BAETICA } \\
\hline Corduba & $\begin{array}{l}C I L \mathrm{II}^{7}, 356 ; E A O R \text { VII, } 22 \\
A E 1962,48 ; C I L \mathrm{II}^{7}, 361=E A O R \text { VII, } 24\end{array}$ \\
\hline Hispalis & CIL II, 1190; CILA II, 1, 37; HEp 2005, 351 \\
\hline \multicolumn{2}{|r|}{ CONSERVVS } \\
\hline \multicolumn{2}{|r|}{ ITALIA } \\
\hline $\begin{array}{l}\text { Thermae } \\
\text { Himeraeae }\end{array}$ & CIL X, 7364; EAOR III, 71 \\
\hline \multicolumn{2}{|r|}{ BAETICA } \\
\hline Corduba & $A E$ 1962, 51; CIL II', 364; EAOR VII, 32; HEp 2009, 123 \\
\hline \multicolumn{2}{|r|}{ CONVICTOR } \\
\hline \multicolumn{2}{|r|}{ ITALIA } \\
\hline Roma & CIL VI, 10169; EAOR I, 86 \\
\hline Beneuentum & $A E$ 1960, 139; $A E$ 1960, 140; EAOR III, 69 \\
\hline Parma & CIL XI, 1070; EAOR II, 46 \\
\hline
\end{tabular}


CÓNYUGES, FAMILIARES Y COMPAÑEROS: APROXIMACIÓN A LA TIPOLOGÍA...

\begin{tabular}{|c|c|}
\hline \multicolumn{2}{|r|}{ EPÍGRAFES GLADIATORIOS CON DEDICANTES VARONES } \\
\hline \multicolumn{2}{|r|}{ COARMIO } \\
\hline \multicolumn{2}{|r|}{ ITALIA } \\
\hline Panhormus & CIL X, 7297; EAOR III, 70 \\
\hline \multicolumn{2}{|r|}{ COGNOMEN } \\
\hline \multicolumn{2}{|r|}{ GALLIA NARBONENSIS } \\
\hline Dea Augusta & CIL XII, 1596; EAOR V, 11 \\
\hline Vienna & CIL XII, 1915; EAOR V, 23 \\
\hline Nemausus & CIL XII, 3331; EAOR V, 26 \\
\hline \multicolumn{2}{|r|}{ CONTVBERNALIS } \\
\hline \multicolumn{2}{|r|}{ AQVITANICA } \\
\hline Auaricum & CIL XIII, 1200; EAOR V, 61 \\
\hline \multicolumn{2}{|r|}{ TIRO } \\
\hline \multicolumn{2}{|r|}{ ITALIA } \\
\hline Roma & CIL VI, 10197; EAOR I, 97 \\
\hline \multicolumn{2}{|r|}{ COMPATRIOTA } \\
\hline \multicolumn{2}{|r|}{ ITALIA } \\
\hline Roma & CIL VI, 7658; EAOR I, 81 \\
\hline \multicolumn{2}{|r|}{ COLLIBERATO } \\
\hline \multicolumn{2}{|r|}{ DALMATIA } \\
\hline Salona & AE 2011, 928; CIL III, 2127; CIL III, 8595 \\
\hline \multicolumn{2}{|r|}{ DOCTOR } \\
\hline \multicolumn{2}{|r|}{ ITALIA } \\
\hline Roma & CIL VI, 10183; EAOR I, 59 \\
\hline $\begin{array}{l}\text { Concordia } \\
\text { Sagittaria }\end{array}$ & CIL V, 1907; EAOR II, 37 \\
\hline Brixia & $C I L \mathrm{~V}, 4502 ; E A O R$ II, 38 \\
\hline \multicolumn{2}{|r|}{ GALLIA NARBONENSIS } \\
\hline Nemausus & $A E$ 1962, 62; CIL XII, 3332 \\
\hline
\end{tabular}


MIGUEL MARTÍNEZ SÁNCHEZ

\begin{tabular}{|c|c|}
\hline \multicolumn{2}{|r|}{ EPÍGRAFES GLADIATORIOS CON DEDICANTES VARONES } \\
\hline \multicolumn{2}{|r|}{ PATRONVS } \\
\hline \multicolumn{2}{|r|}{ ITALIA } \\
\hline Roma & CIL V, 3459; EAOR II, 49 \\
\hline \multicolumn{2}{|r|}{ GERMANIA INFERIOR } \\
\hline $\begin{array}{l}\text { Colonia Clau- } \\
\text { dia Ara }\end{array}$ & $A E$ 1941, 87; $A E$ 1945, 13; $A E$ 1948, 230; EAOR V, 65 \\
\hline \multicolumn{2}{|r|}{ SODALIS } \\
\hline \multicolumn{2}{|r|}{ ITALIA } \\
\hline Roma & CIL VI, 7659; EAOR I, 83 \\
\hline \multicolumn{2}{|r|}{ DALMATIA } \\
\hline Salona & $A E$ 1934, 284; $A E$ 1961, 307; $A E$ 2001, 1622; AE 2011, 928 \\
\hline \multicolumn{2}{|r|}{ GALLIA NARBONENSIS } \\
\hline Nemausus & $\begin{array}{l}\text { EAOR } \mathrm{V}, 14 \\
\text { EAOR } \mathrm{V}, 19\end{array}$ \\
\hline \multicolumn{2}{|r|}{ GERMANIA INFERIOR } \\
\hline $\begin{array}{l}\text { Colonia Clau- } \\
\text { dia Ara }\end{array}$ & $A E 1929,110 ; E A O R \mathrm{~V}, 63$ \\
\hline \multicolumn{2}{|r|}{ AMICVS } \\
\hline \multicolumn{2}{|r|}{ ITALIA } \\
\hline Roma & $A E$ 1989, 185; CIL VI, 10190; EAOR I, 90 \\
\hline Brixia & CIL V, 4511; EAOR II, 51 \\
\hline \multicolumn{2}{|r|}{ DALMATIA } \\
\hline Salona & $A E$ 1934, 284; $A E$ 1961, 307; $A E$ 2001, 1622; $A E$ 2011, 928 \\
\hline \multicolumn{2}{|r|}{ GALLIA NARBONENSIS } \\
\hline Narbo & CIL XII, 4452; EAOR V, 29 \\
\hline \multicolumn{2}{|r|}{ FRATER } \\
\hline \multicolumn{2}{|r|}{ ITALIA } \\
\hline Roma & $C I L$ VI, 10180; EAOR I, 75 \\
\hline Ostia & $A E$ 1985, 197; EAOR I, 84 \\
\hline
\end{tabular}


CÓNYUGES, FAMILIARES Y COMPAÑEROS: APROXIMACIÓN A LA TIPOLOGÍA...

\begin{tabular}{|c|c|}
\hline \multicolumn{2}{|r|}{ EPÍGRAFES GLADIATORIOS CON DEDICANTES VARONES } \\
\hline \multicolumn{2}{|r|}{ DALMATIA } \\
\hline Salona & $A E$ 2001, 1622; AE 2011, 928; CIL III, 8830 \\
\hline \multicolumn{2}{|r|}{ BAETICA } \\
\hline Corduba & CIL II ${ }^{7}, 356 ;$ EAOR VII, 22 \\
\hline \multicolumn{2}{|r|}{ FAMILIA GLADIATORIA / FAMILIA VNIVERSA } \\
\hline \multicolumn{2}{|r|}{ ITALIA } \\
\hline Roma & CIL VI, 10168; EAOR I, 79 \\
\hline \multicolumn{2}{|r|}{ BAETICA } \\
\hline Corduba & $A E$ 1952, 126; AE 1962, 49; CIL II ${ }^{7}, 362 ; E A O R$ VII, 19 \\
\hline \multicolumn{2}{|r|}{ ¿COLLEGIVM? } \\
\hline \multicolumn{2}{|r|}{ ITALIA } \\
\hline Roma & CIL VI, 37843 \\
\hline \multicolumn{2}{|r|}{ FILIVS } \\
\hline \multicolumn{2}{|r|}{ ITALIA } \\
\hline Roma & $\begin{array}{l}\text { CIL VI, 10177; CIL VI, 33977; CIL XIV, 293,2; EAOR I, } 73 \\
\text { CIL VI, 10176; EAOR I, } 74\end{array}$ \\
\hline \multicolumn{2}{|r|}{ LIBERTVS } \\
\hline \multicolumn{2}{|r|}{ ITALIA } \\
\hline Roma & AE 1888, 83; CIL VI, 33983; EAOR I, 64 \\
\hline
\end{tabular}

bajo lo representaban los tirones, luego iban los distintos rangos de gladiadores ueterani, a continuación los magistri y doctores y, por último, el lanista"29. Pasado el tiempo, el gladiador se convertía en un combatiente altamente entrenado en las armas, de ahí que muchos políticos los usasen de guardaespaldas (Tac. ann. 13.25.3; Cod. Theod. 15.12.3, Impp. Arcadius et Honorius AA. Ad Pop.). Este orgullo "militar" se transmite en la muerte del gladiador como guerrero (Sen. dial. 2, 16.2; Cic. Phil. 3.14.35) y se ve reflejado en que se haga enterrar junto a sus compañeros, en acto de hermandad. De ese modo, la familia gladiatoria se entiende con el mismo significado que la biológica, lo cual explicaría el uso de frater en algunos dedicantes. Fuesen esclavos, auctorati o noxii, la familia era prácticamente todo lo que un gladiador conservaba.

\footnotetext{
29 Pastor y Pastor 2013a: 135.
} 


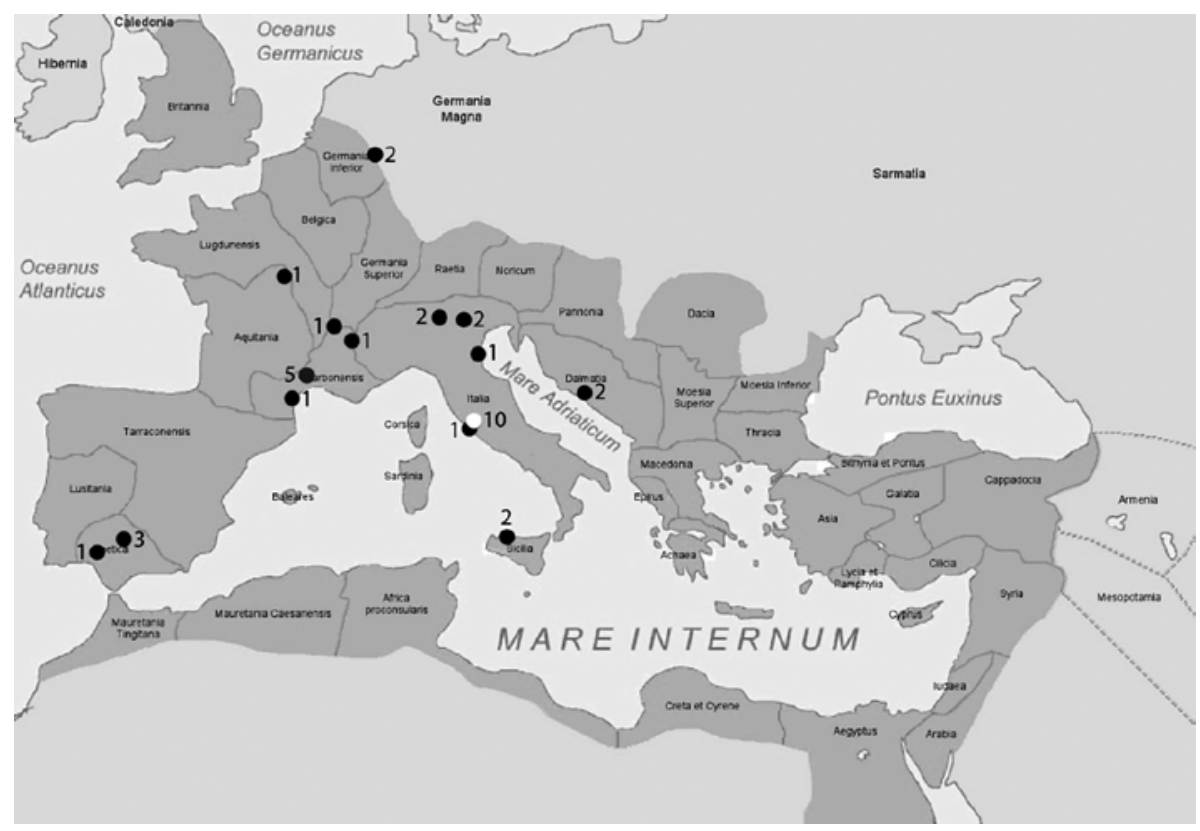

Figura 2. Mapa con los dedicantes masculinos en las provincias occidentales.

\section{CARACTERísticas de los DEDiCANTES DE LOS EPíGRAFES FUNERARIOS DE GLADIADORES}

Una vez hemos visto los resultados, observamos algunas diferencias con otros artículos ya publicados. Sobre las dedicantes mujeres, Francisco Cidoncha Redondo afirma que hay un total de 44 inscripciones donde existe una clara relación sentimental o familiar entre un gladiador y una mujer, si bien en un artículo anterior de Alberto Ceballos Hornero se afirma que se conservaba en el registro epigráfico un total de 111 lápidas, de las cuales 77 conservaban el dedicante, 36 de ellos de mujeres. En nuestro recuento, el porcentaje sigue siendo similar. con algo más de la mitad de dedicantes con nombre femenino (58\%) frente al resto, enmarcado en el entorno del ludus del combatiente (42\%).

Respecto a la denominación que aparece en todo el registro, vemos que hay un claro protagonismo del término coniunx respecto al resto, mientras que no parece existir una predilección por el uso de contubernalis, lo cual contradice la estructura legal transmitida en las fuentes. Por su parte, entre los compañeros del ludus hay una predilección por dejar la impronta de la armatura en el monumento funerario, acompañada casi siempre del cognomen artístico.

Sobre la condición social, en todo el conjunto de inscripciones de gladiadores, encontramos denominaciones con tria nomina, con duo nomina o simplex. Sabemos que, a partir del primer combate, los gladiadores tomaban un cognomen 


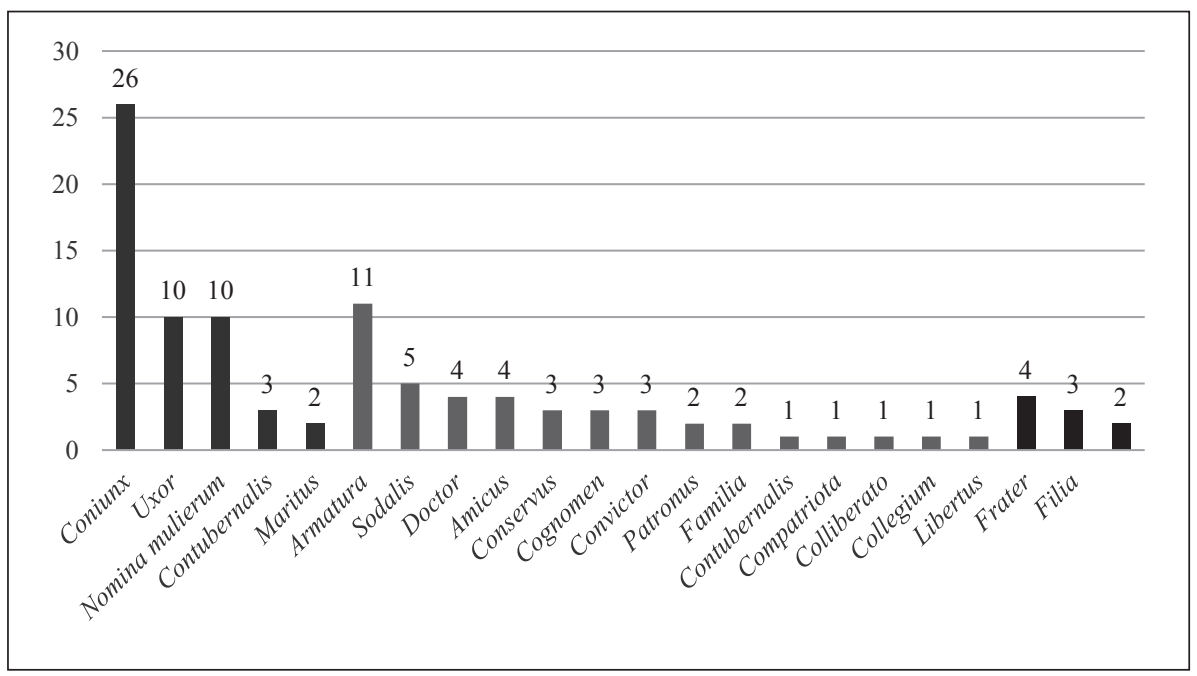

Figura 3. Términos que aparecen en el registro epigráfico de dedicantes en la epigrafía gladiatoria.

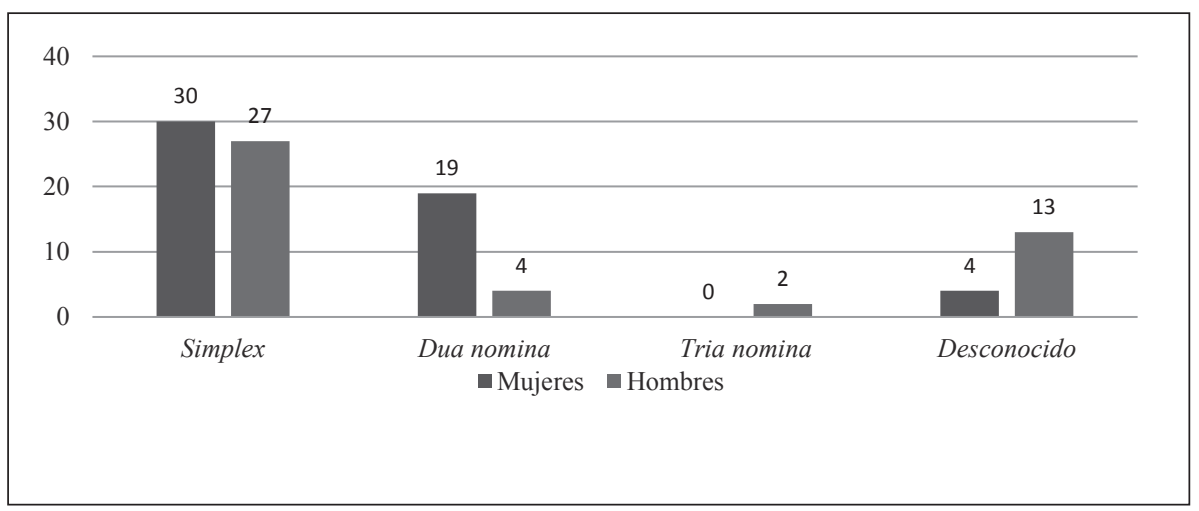

Figura 4. Distribución de los nomina por sexo.

artístico y daban comienzo a su nueva vida. Esto nos provoca un problema a la hora de enfrentarnos a las diferentes teorías sobre su condición legal. Si nos atenemos a los ejemplos que aquí citamos, en las 86 inscripciones encontradas, el perfil de la onomástica no sigue un patrón fijo. En el caso de las mujeres, conservamos 53 alusiones en total, de las cuales 30 muestran su cognomen, 19 duo nomina y 4 casos donde no aparece nombre. En el caso de los varones, aparecen 27 casos con cognomen, 4 con duo nomina y 2 casos de tria nomina, junto con 13 casos donde no se especifica nombre.

Respecto a los dos casos donde se conserva tria nomina, el primero es un doctor (CIL XII, 3332) de nombre Lucius Sestius Latinus, encontrado en Nimes. 
El otro caso es el de un gladiador enterrado en Corduba, el murmillo contrarete Probus, del ludus Pauliano, cuyos dedicantes son su esposa y su hijo (CIL II ${ }^{7}$, 363). Aquí, la esposa, de nombre Volumnia Sperata, aparece acompañada de su hijo, Publius Volumnius Vitalis, el cual lleva tria nomina, conservando el nomen de su madre, luego Probus pudo ser un liberto trabajando de gladiador en calidad de auctoratus o bien un esclavo con una mujer liberta, de ahí que el hijo adquiriese el nomen de la madre ${ }^{30}$. Este ejemplo nos ayuda a normalizar la figura del gladiador, convirtiéndola en una profesión más y no solamente un fenómeno asociado a una condena o a la esclavitud ${ }^{31}$.

De acuerdo con Mauricio Pastor, distinguiríamos varias categorías para explicar la llegada a la gladiatura ${ }^{32}$ : por condena (noxii ad gladium o damnati ad bestias), los condenados a trabajos forzosos (entregados a un lanista), los esclavos y los voluntarios o auctoratii, una categoría aparte, en la cual se mantenía la libertad ${ }^{33}$. Sobre los esclavos o los condenados ad ludum, podían conseguir su libertad triunfando en la arena ${ }^{34}$, dándose el caso de que muchos seguían su actividad en el ludus, bien como entrenadores (doctores, magistri) o volviendo a la arena con la función de árbitro (summa rudis) ${ }^{35}$. Esta categoría estaba reservada solo para los gladiadores de élite, expertos conocedores de las normas y, en última instancia, responsables del desarrollo del combate $^{36}$.

Por último, destacamos fuera del territorio de la Península Itálica dos centros neurálgicos con una alta concentración de inscripciones de gladiadores: la necrópolis al sur del anfiteatro de $\operatorname{Nimes}^{37}$ y la colección de inscripciones conservada en Córdoba ${ }^{38}$. De hecho, los epígrafes de Colonia Patricia Corduba son la mayor colección de este tipo fuera del territorio de la ciudad de Roma y suponen el 80\% de las inscripciones de toda Hispania, por lo que se ha especulado que se trate del Ludus Hispanianus ${ }^{39}$. El análisis y comentario más extenso de estas piezas se encuentra recogido en diferentes publicaciones ${ }^{40}$, quedando todavía abierto el debate sobre la localización de este ludus.

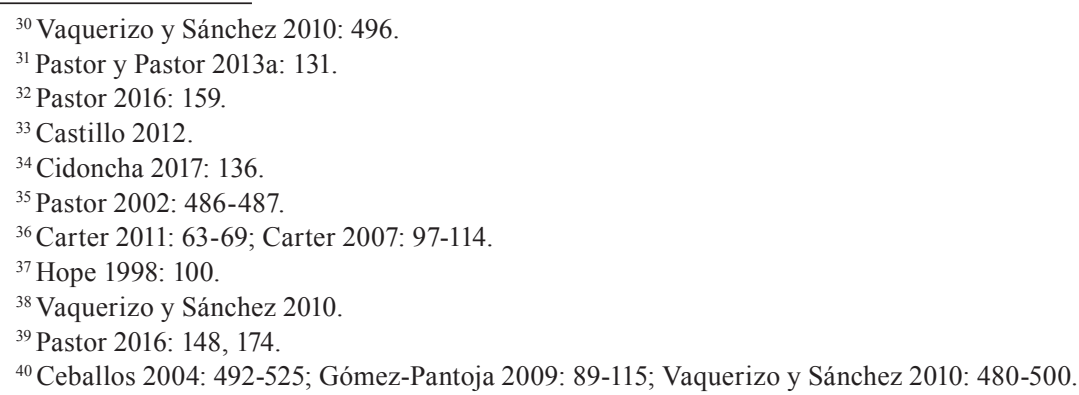




\section{ConClusiones}

Nos encontramos en un punto de la investigación en el que vemos en el universo que rodea a los gladiadores toda una gama de grises que nos aleja del viejo relato de la gladiatura basada exclusivamente en la esclavitud o el libre ejercicio por parte de los auctorati. No podemos ver desde un solo punto de vista un proceso que abarcó tantos siglos y que significó no solo una forma de vida o un negocio itinerante, sino también una herramienta para el desarrollo de las carreras políticas locales y la propaganda política. Este nexo con la actividad política en las prouinciae y municipia es el que explica que gran parte de los epígrafes sean de época altoimperial, el periodo cronológico de mayor concentración para prácticamente toda la actividad epigráfica del Imperio Romano. Todavía queda por conocer mejor el funcionamiento interno de los munera, especialmente en las provincias fuera de Italia, donde los negocios contaban con más dificultades para el abastecimiento de recursos humanos necesario en este espectáculo (lanistas, personal entrenado, escuelas itinerantes o fijas, árbitros, etc.).

La compilación de los dedicantes de las obras epigráficas funerarias de gladiadores nos permite entender cómo, más allá de la arena, los combatientes tuvieron relaciones sociales y desarrollaron su vida privada. Queda abierta la incógnita sobre si fue posible que llegaran a establecerse en matrimonium iustum, debido a la denominación que utilizan las mujeres en la epigrafía (coniunx o uxor), términos que escapan a la mera aplicación de la legalidad vigente en la época. Esta cuestión esconde muchos problemas de interpretación para los historiadores, quienes incluso con las fuentes y la epigrafía en la mano no podemos salvar del todo la verdadera interpretación, jurídica o puramente sociocultural, que los responsables del acto epigráfico hacían sobre su relación de pareja con los gladiadores fallecidos. Sabemos que muchas mujeres portadoras de duo nomina fueron esposas de gladiadores, al igual que muchos de sus hijos se representaron a sí mismos como libertos. Es posible, como afirma Robert Knapp ${ }^{41}$, que las clases bajas viviesen en una órbita legal paralela a la literalidad de las fuentes y la ley romana, lo cual abriría la posibilidad a la existencia de casos como que un gladiador con tria nomina pudiese enterrarse con su cognomen artístico, anteponiendo su identidad social respecto a su entorno más cercano frente a su identidad estrictamente legal en cuanto a ciudadanía.

Fuesen matrimonios justos o no, fuesen esclavos o no, los epígrafes son reveladores de una visión más íntima sobre la realidad en la que vivieron los gladiadores. Encontramos el cariño de los compañeros, el amor de las parejas y el respeto y la honra de los hijos a sus progenitores. Queda para el futuro conocer mejor el papel que tuvieron los editores y los lanistae, encargados unos de la organización de estos juegos y otros de la gestión de los negocios de la gladiatura.

\footnotetext{
${ }^{41}$ Knapp 2011: 11.
} 
También permanece abierta la incógnita sobre la calidad de vida media del gladiador, la cual dependía de si el negocio en el que trabajaba era rentable tanto para sus dueños como para el estado romano, el cual en época de Marco Aurelio llegó a obtener nada menos que 30 millones de HS anuales de los beneficios de los $m u$ $n e r a^{42}$. Por último, una vez conozcamos las diferentes casuísticas provinciales, entenderemos mejor los rasgos socioeconómicos de los gladiadores en las diferentes regiones, para quienes la meta no fue ganar en la arena, sino pelear contra la dureza de sus vidas.

\section{BiBLIOGRAFÍA}

AA VV 2017: AA.VV., Desperta Ferro, Arqueología e Historia (ejemplar dedicado a: Gladiadores) (Madrid 2017), no 14.

Bendala 1973: M. Bendala, “Tablas de juego en Itálica”, Habis 4 (1973) 263-272.

Blázquez 1958: J. M. Blázquez, "Representaciones de gladiadores en el Museo Arqueológico Nacional”, Zephyrus 9 (1958) 79-94.

Carter 2007: M. J. Carter, "Gladiatorial Combat: The Rules of Engagement", CJ 102, 2 (2007) 97-114.

Carter 2011: M. J. Carter, "Blown call? Diodorus and the Treacherous Summa Rudis", ZPE 177 (2011) 63-69.

Ceballos 2003: A. Ceballos, "Epitafios latinos de gladiadores en el occidente romano", Veleia 20 (2003) 315-330.

Ceballos 2004: A. Ceballos, "Los espectáculos en la Hispania romana: la documentación epigráfica”, Cuadernos emeritenses 26 (1) (2004) 5-683.

Ceballos y Ceballos: 2011: A. Ceballos y D. Ceballos, "La nominación de los espectáculos romanos en la epigrafía provincial del Occidente latino", Emerita 79 (1) (2011) 105-130.

Cidoncha 2017: F. Cidoncha, "Los gladiadores, sus mujeres e hijos en las provincias occidentales del Imperio Romano”, Anesteria 6 (2017) 133-147.

Crowther 2007: N. B. Crowther, Sport in Ancient Times (Westport 2007).

Del Pino 2011: E. Del Pino, "Sobre la inscripción latina no 4625 del Museo de Cádiz y el gladiador griego llamado Germanus", Habis 42 (2011) 173-190.

Dunkle 2013: R. Dunkle, Gladiators. Violence and Spectacle in Ancient Rome (New York 2013).

Edmonson 1996: J. C. Edmonson, "Dynamic Arenas: Gladiatorial Presentations in the City of Rome and the Construction of Roman Society during the Early Empire", en W. Slater (ed.), Roman Theater and Society (Ann Arbor 1996) 69-112.

\footnotetext{
${ }^{42}$ Manodori 1989: 22.
} 
Edwards 1997: C. Edwards, "Unspeakable Proffessions: Public Performance and Prostitution in Ancient Rome", en J. Hallet y M. Skinner (eds.), Roman sexualities (Princeton 1997) 66-98.

Edwards 2007: C. Edwards, Death in Ancient Rome (New Haven 2007).

Egea y Arias 2015: A. Egea y L. Arias, "Russell Crowe el gladiador, Colón el descubridor y otros protagonistas de la Historia. Buceando en las narrativas históricas de jóvenes universitarios españoles", Clio: History and History Teaching 41 (2015) 1-28.

Eguiarte 2012: E. A. Eguiarte, "Los espectáculos del anfiteatro en San Agustín y sus implicaciones espirituales", Augustinus: revista trimestral publicada por los Padres Agustinos Recoletos 57 (2012) 75-97.

Enenkel 2005: K. Enenkel, "The propagation of fortitude. Gladiatorial combats from ca. $85 \mathrm{BC}$ to the times of Trajan and their reflection in Roman literature", en K. Enenkel e I. Pfeijffer (eds.), The manipulative mode. Political propaganda in antiquity. A collection of case studies (Leiden 2005) 275-294.

Erme 2014: E. Erme, "Orígenes (raíces) de la Medicina del Deporte", Archivos de medicina del deporte: revista de la Federación Española de Medicina del Deporte y de la Confederación Iberoamericana de Medicina del Deporte 162 (2014) 263-267.

Futrell 2006: A. Futrell, The Roman Games. A Sourcebook (London 2006).

Giménez 2010: I. Giménez, “Espartaco: ¿El Ché Guevara de la Antigüedad?”, Clio: Revista de Historia 104 (2010) 14-23.

Gómez-Pantoja 2006: J. Gómez-Pantoja, "Entre Italia e Hispania: los gladiadores", en A. Sartori y A. Valvo (eds.), Hiberia-Italia, Italia-Hiberia (Milano 2006) 167-180.

Gómez Pantoja 2009: J. Gómez-Pantoja, Epigrafia anfiteatrale dell'occidente romano. VII. Baetica, Tarraconense, Lusitania (Roma 2009).

González 2013: R. González, "Los primeros cristianos y la damnatio ad bestias: una visión crítica", en G. Bravo y R. González (coords.), Formas de morir y formas de matar en la Antigüedad romana (Madrid 2013).

Grosschmidt y Kanz 2002: K. Grosschmidt y F. Kanz, Gladiatoren in Ephesos. Tod am Nachmittag (Wien 2002).

Guttmann 1978: A. Guttmann, From Ritual to Record (New York 1978).

Hope 2000: V. Hope, "Fighting for identity: the funerary commemoration of Italian gladiators", The epigraphic landscape of Roman Italy (London 2000) 93-113.

Hope 1998: V. Hope, "Negotiating identity and status: the gladiators of Roman Nimes", en R. Laurente y J. Berry (eds.), Cultural identity in the Roman Empire (London-New York 1998) 179-185.

Jiménez 2009: J. A. Jiménez, "La desaparición de los espectáculos de gladiadores en Hispania", HAnt 33-34 (2009) 273-293. 
Jiménez 2011: J. A. Jiménez, “Obispos y gladiadores: el recurso a los profesionales del anfiteatro en disputas por la elección episcopal”, Polis 23 (2011) 89-113.

Junkelmann 2000: M. Junkelmann, "Familia gladiatoria: The Heroes of the Amphitheatre", en W. Köhne, y C. Ewigleben (eds.), Gladiators and Caesars. The Power of Spectacle in Ancient Rome (Berkeley 2000) 40-67.

Kanz y Grosschmidt 2006: F. Kanz y K. Grosschmidt, "Head injuries of Roman gladiators", Forensic Science International 160 (2006) 207-216.

Knapp 2011: R. C. Knapp, Los olvidados de Roma. Prostitutas, forajidos, esclavos, gladiadores y gente corriente (Barcelona 2011).

Köhne y Ewigleben 2000: E. Köhne y C. Ewigleben, Gladiators and Caesars. The Power of Spectacle in Ancient Rome (Berkeley 2000).

Kyle 1998: D. G. Kyle, Spectacles of Death in Ancient Rome (New York 1998).

López y Pérez 2017: M. J. López y F. Pérez, "El munus en honor de Julia organizado por César: ritual funerario, desigualdad social y propaganda política en la Roma republicana", Arys: Antigüedad: religiones y sociedad 15 (2017) 145-170.

Mahoney 2001: A. Mahoney, Sports and Spectacles (Newburyport 2001).

Mann 2011: Ch. Mann, "Um keinen Kranz, um das Leben kämpfen wir!” Gladiatoren im Osten des Römischen Reiches und die Frage der Romanisierung (Berlin 2011).

Manodori 1982: A. Manodori, Anfiteatri, circhi e stadi di Roma (Roma 1982).

Mañas 2013: A. Mañas, Gladiadores, el gran espectáculo de Roma (Madrid 2013).

Mendoza 2018: D. Mendoza, "Espectáculos romanos imperiales en las fuentes históricas", Materiales para la Historia del Deporte 17 (2018) 42-59.

Muñoz 2016a: M. E. Muñoz, "Anfiteatros y ludi gladiatorii: las fuentes clásicas e Hispania como ejemplo", Saitabi 62-63 (2016) 27-38.

Muñoz 2016b: M. E. Muñoz, "Gladiadores romanos: la historia de sus espectáculos", Clio: revista de Historia 180 (2016) 52-59.

Muñoz 2017a: M. E. Muñoz, "Espectáculos, Antigua Roma, Venationes: la caza de animales en espectáculos romanos”, Clio: revista de Historia 181 (2017) 80-87.

Muñoz 2017b: M. E. Muñoz, "El gladiador que pasó de las manos de una dama a las de un caballero ¿el mango de espejo de Emporiae? Una revisión”, Sylloge epigraphica Barcinonensis 15 (2017) 221-228.

Naselli 2010: D. Naselli, "El disciplinamiento de gladiadores en el Imperio Romano", Huellas de la Historia 6 (2010) 1-28.

Pastor 2002: M. Pastor, "Munera gladiatorum: aspectos sociales", en A. Alonso y S. Crespo (Coords.). Scripta Antiqua: in honorem Angel Montenegro Duque et José María Blázquez Martínez (Valladolid 2002) 485-499.

Pastor 2016: M. Pastor, "Munera gladiatoria en Hispania", FlorIlib 27 (2016) 141-182. 
Pastor 2018: M. Pastor, Los gladiadores. El fascinante espectáculo de los munera gladiatoria en el mundo romano (Granada 2018).

Pastor y Mañas 2010: M. Pastor y A. Mañas, "Munera gladiatorum. Origen del deporte espectáculo de masas", FlorIlib 21 (2010) 291-321.

Pastor y Mañas 2012: M. Pastor y A. Mañas, "Munera gladiatoria, mujeres gladiadoras", FlorIlib 23 (2012) 127-151.

Pastor y Pastor 2009: M. Pastor y H. F. Pastor, "La profesión de gladiador en Mauritania Tingitana”, Florentia Iliberritana 20 (2009) 171-199.

Pastor y Pastor 2013a: M. Pastor y H. F. Pastor, "Educación y entrenamiento en el ludus", FlorIlib 24 (2013) 127-152.

Pastor y Pastor 2013b: M. Pastor y H. F. Pastor, "Muerte en la arena. Formas de morir de los gladiadores", en G. Gravo y R. González (coords.), Formas de morir y formas de matar en la Antigüedad romana (Madrid 2013) 203-227.

Pastor y Pastor 2013c: M. Pastor y H. F. Pastor, "Guerra y Mvnvs gladiatorivm", en A. Pociña y J. García (coords.), La paz y la guerra (Madrid 2013) 259-276.

Perea 2012: S. Perea, "El papel de los gladiadores en la trama criminal de los idus de marzo del 44 a. C. según Bioç Kaisapoç, de Nicolás de Damasco", Gerión 30 (1-2) (2012) 169-184.

Piernavieja 1972: P. Piernavieja, "Ludia: un terme sportif latin chez Juvénal et Martial”, Latomus 31 (1972) 1037-1040.

Plass 1995: P. Plass, The Game of Death in Ancient Rome. Arena Sport and Political Suicide (Madison 1995).

Potter 2006: D. S. Potter, A Companion to the Roman Empire (Oxford 2006) 385-408.

Requejo 1981: J. Requejo (trad.). Agrícola. Germania. Diálogo sobre los oradores (Madrid: Gredos 36, 1981).

Robert 1940: L. Robert, Les Gladiateurs dans l'Orient grec (Paris 1940).

Sabbatini 1988: P. Sabbatini, "Gli spettacoli anfiteatrali alla luce di alcune testimonianze epigrafiche", en M. Conforto et al. (eds.), Anfiteatro Flavio: immagine, testimonianze, spettacoli (Roma 1988) 194-196.

Scobie 1988: A. Scobie, "Spectator Security and Comfort at Gladiatorial Games", Nikephoros 1 (1988) 191-243.

Syme 1939: R. Syme, The Roman Revolution (Oxford 1939).

Vaquerizo 2011: D. Vaquerizo, "De la agonía al luto. Muerte y funus en la Hispania romana", en C. Pacheco (coord.), La Muerte en el tiempo. Arqueología e Historia del hecho funerario en la provincia de Toledo (Toledo 2011) 95-125.

Vaquerizo y Sánchez 2010: D. Vaquerizo y S. Sánchez, "Epigrafía gladiatoria cordubense", en D. Vaquerizo y J. F. Murillo (eds.), El anfiteatro Romano de Córdoba y su entorno urbano, análisis arqueológico (ss. I-XIII d. C.) (Córdoba 2010) 480-500.

Ville 1981: G, Ville, La gladiature en Occident des origines à la mort de Domitien (Roma 1981).

Wiedermann 1992: T. Wiedermann, Emperors and Gladiators (New York 1992). 


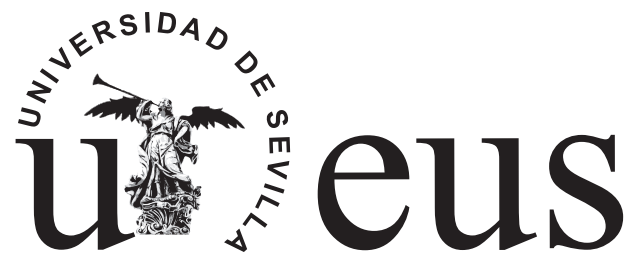

Editorial Universidad de Sevilla

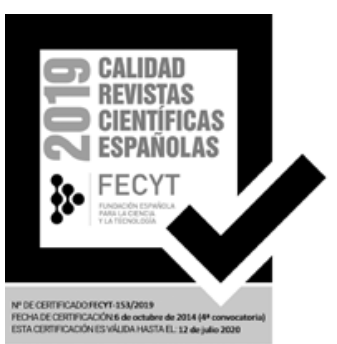

